
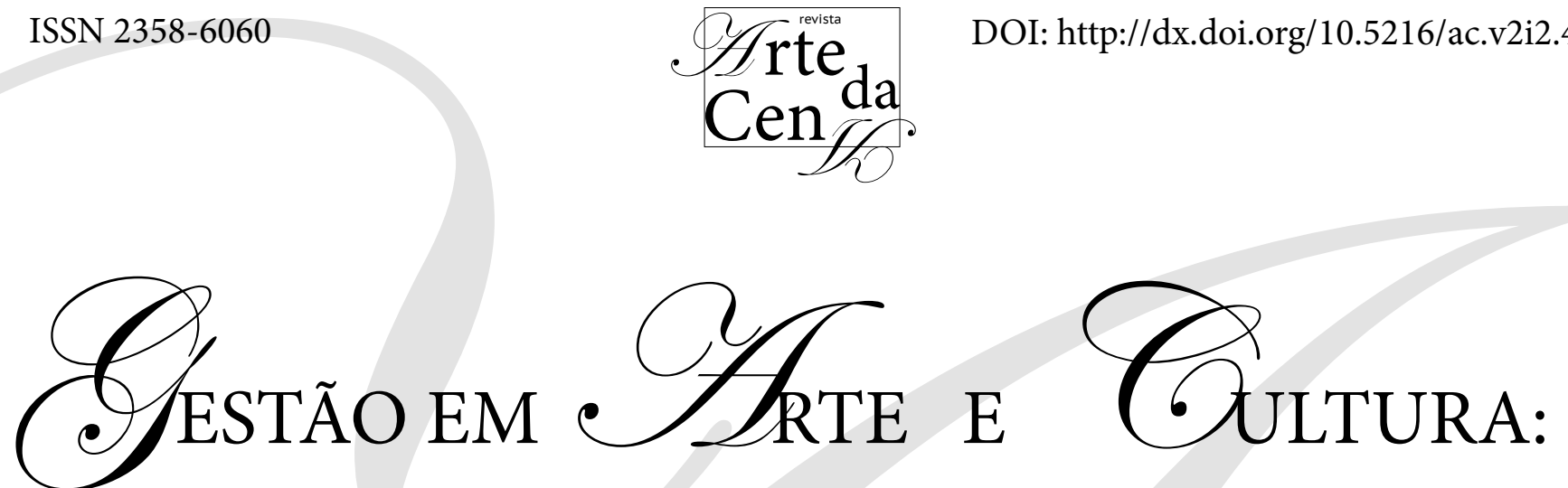

\title{
APRESENTAÇÃO DE UM PROJETO, FERRAMENTAS E METODOLOGIAS, DESDOBRAMENTOS
}

"Management in Art and Culture:

Presentation of a Project, Tools and Methodologies, Developments"

Marcio Pizarro Noronha*

Professor do Programa de Pós-Graduaçao em História e da Licenciatura em Dança da Universidade Fedeal de Goiás

RESUMO: Artigo de apresentação do projeto financiado pelo Fundo Estadual denominado Gestão em Arte e Cultura. Analisa e articula diferentes artigos e pontos de vista e apresenta aspectos de uma metodologia de investigação para o campo da gestão em artes.

Palavras-chave: Gestão em arte; Fundo Cultural: metodologias de pesquisa em gestão em arte e cultura.

ABSTRACT: This article presents a project funded by the State Fund, called Art and Culture Management. Analyzes and articulates diferente articles and point of views and presentes aspects of a research methodology to the field of arts management.

Keywords: Management in art; cultural fund; research methods in managent in art and culture. 


\section{I- Abertura}

Este artigo nasceu de uma tripla demanda ou desdobramento de desejos. O primeiro ponto é a tarefa da realização de um dossiê ou publicação impressa referente ao problema da Gestão em arte e cultura, investigando especialmente aspectos das relações entre instituições de arte e cultura e espaços independentes e autônomos, questões referentes aos papéis de produtor, curador e gestor no campo das artes, aspectos de políticas e de economias para pensar o setor artístico e relatos de experiências. $\mathrm{O}$ segundo aspecto ou demanda é de realizar uma apresentação do projeto realizado através do Fundo Estadual de Cultura (GO), relatando aspectos do seu desenvolvimento e seus atores e interlocutores. $\mathrm{O}$ terceiro é o de propiciar um espaço para a escrita de um texto teórico e metodológico no que tange aos problemas da temática da gestão em artes, na cena das produções artísticas contemporâneas, realizando um esforço transdisciplinar entre campos de conhecimento que envolvem gestão, administração, política, políticas públicas, história dos bens, produtos e equipamentos culturais e artísticos, relatos de experiência, memória, economia e, fundamentalmente, numa busca em ressaltar as particularidades de pensar todas estas questões para o universo das artes, recuperando a força do termo e partindo de uma premissa epistemológica e política da importância em manter a separação, ou, no mínimo, as zonas de tensão entre arte e cultura.

Estes três desejos serão apresentados na seguinte forma de organização. Em primeiro lugar vou realizar uma apresentação e cruzamento dos demais textos apresentados neste conjunto de artigos e ainda ressaltar a presença de outros interlocutores que não comparecem sob a forma escrita mas que integraram o projeto original financiado pelo Fundo Estadual de Cultura.

O segundo aspecto é o do exercício entre a teoria e a metodologia de trabalho, especialmente apontando para reflexões que tenho realizado nos últimos cinco anos.

O terceiro aspecto apontará algumas questões referentes a este projeto editorial.

\section{II- Entrecruzamentos textuais.}

O projeto Gestão em Arte e Cultura (Fundo Estadual de Cultura) foi organizado sob o molde de residências autônomas com diferentes convidados brasileiros e membros da comunidade latino-americano, falantes de língua espanhola, envolvendo experiências em países como Argentina, Chile e México, bem como do Norte, do Centro-Oeste e do Sul do Brasil. Nossos convidados tinham a tarefa de realizar 


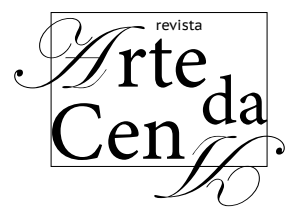

residências nos formatos os mais diversos, sem caracterizar uma estrutura de cursos, e, o meu e nosso papel (da equipe de gestão e produção) era o de desenhar possíveis interlocuções entre os diferentes momentos e residências, num período de seis meses de trabalho. Num segundo momento, após as experiências e ressaltadas as demandas, realizar a produção de textos artigos, relatos de experiência, ensaios - para a publicação em dois formatos - revista eletrônica e revista impressa e, posteriormente, ampliados, a publicação de um livro eletrônico (e-book) e um livro impresso. Neste momento do projeto, sentimos a necessidade de abrir a interlocução a outros agentes que discutem gestão e produção e que não puderam estar presentes como nossos parceiros presenciais e nestes termos, o dossiê esteve aberto à recepção e avaliação de artigos, bem como a convites a pesquisadores reconhecidos na discussão dos temas que envolvem o campo transdisciplinar dos estudos da gestão.

Assim, resultam num conjunto de textos que envolvem os temas da gestão em artes no sentido amplo do termo, nas reflexões que envolvem as pesquisas do grupo da Curatoria Forense, aqui representados no artigo "Uma pretensão libertadora e uma predisposição de ordem: gestões autônomas de arte contemporânea na América Latina”, de Jorge Sepúlveda e Guillermina Bustos (Chile, Argentina e Brasil), também editores responsáveis por diversas publicações e programas de cartografias e mapeamentos das artes na América Latina ${ }^{1}$, cujo foco é o de apresentar a estrutura dos seus programas e a metodologia de trabalho aplicada nos grupos de gestão autônoma em artes, envolvendo formas de trabalho coletivo e colaborativo e as relações que entretecem com o vasto campo institucional (das instituições de artes e seus programas de fomento), com base no exercício de uma economia e de uma política das incertezas e da provisoriedade, e, o trabalho da pesquisadora doutora Ilze Petroni (Argentina), cujo título é "Exercício de Desconstrução: apontamentos sobre gestão autônoma e o campo artístico contemporâneo". O artigo de Petroni obedece o regime ensaístico de texto de cunho filosófico, desenvolvendo um tipo de pensamento especulativo e crítico referente à constituição da experiência das gestões autônomas e seus limites. A autora, reforçando uma leitura marxiana e pós-marxiana, numa conversa entre sociologia e filosofia, observa o modo como a autonomia é uma zona limítrofe do microcosmo designado como campo das artes.

$\mathrm{Na}$ sequência, temos dois artigos concentrados nas artes da cena, com ênfase para a abordagem do mundo da dança. Um deles da pesquisadora Marila Vellozo (Paraná, Brasil) e outro de Miguel Sisto Júnior (Rio Grande do Sul, Brasil). No texto de Vellozo a base para a 
escrita é um conjunto documental referente à história das políticas de cultura na área da dança no âmbito federal. "Formação e produção na dança: entrecruzamentos dos principais 'nós' da área" observa a presença da Funarte como órgão formulador e executor de políticas para as artes no Brasil e demonstra a forte marca da ausência / da falta de um modelo gerador de correlações entre a formação artística e a produção em artes nas políticas de arte e cultura. Esta observação documental do contexto histórico demonstra que há uma demanda reprimida por formação artística que deve e pode ser sanada com a ampliação das concepções das políticas estatais de arte e cultura e a urgência no aumento dos fomentos para programas de cunho formativo. Neste sentido, o texto aponta para um dado sintomal e, ao mesmo tempo, se insere no movimento realizado pelo projeto do qual passa a ser interlocutor. $\mathrm{O}$ programa de gestão em arte e cultura se identifica com o diagnóstico apontado pelo texto de Vellozo e se pensa como parte integrante de uma exigência de cunho formativo para os produtores, artistas e gestores.

O segundo texto que diz respeito às artes da cena e, mais especialmente ao universo da dança, é o artigo na forma de relato de experiência, de Miguel Sisto Junior. Com ampla trajetória de atuação no campo da produção artística e cultural, Sisto se coloca, numa perspectiva êmica, como integrante de uma cadeia econômica da dança. "O produtor-gestor artístico em seu rótulo e em seu selo" traça um relato acerca do desenvolvimento e da tipologia e estereotipia associada ao papel e ator social designado como produtor cultural e de arte. $\mathrm{O}$ produtor, figura histórica e importante agente na complexa trama da gestão das artes da cena, é apresentado a partir de diferentes experiências e observações críticas referentes à produção artística na cidade de Porto Alegre (RS). Ao fim, o autor propõe uma polêmica em torno da tipologia do papel do produtor e as possíveis saídas desta zona de confrontação. Tal como no bloco anterior, dos textos sobre gestão e autonomia, temos a presença de um texto no formato do artigo científico e do artigo de relato de experiência, baseado na presença do seu agente e autor no meio artístico.

Sisto ainda mantém uma breve interlocução com a perspectiva apontada pelo trabalho de Curatoria Forense, na exigência de uma separação entre os domínios da arte e da cultura, apontando estas diferenças para a produção e a gestão em artes e a produção e a gestão em projetos culturais.

Mais dois artigos integram este Dossiê e conjunto de reflexões, são eles, os que envolvem a organização espacial, arquitetônica, as instituições, a memória, a documentação, a preservação e as formas atuais de gestão e planejamento bem 


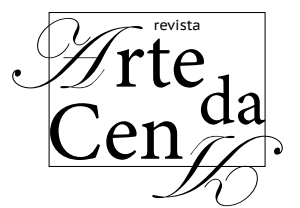

como seus aspectos políticos. São os trabalhos de professora doutora Valquíria Guimarães Duarte (UFG FAV) e da professora mestra Ednair Rodrigues Nascimento, ressaltando suas importantes experiências e currículos no domínio da gestão e do planejamento.

Duarte faz uso do conceito de Performance Process, cunhando durante o desenvolvimento de seu projeto de doutorado em História (UFG FH PPGH), sob minha orientação, e as reflexões em torno da temática do planejamento estratégico, para pensar a problemática da gestão das ações artísticas nos espaços institucionais tomados também como lugares arquitetônicos - edificações, espaços construídos. A autora propõe refletir sobre modos de incorporar temas da gestão e da gestão estratégica, entendida conceitual e metodologicamente, e utilizadas nas experiências da arquitetura para o domínio das artes, suas práticas e ações artísticas. A gestão seria um princípio para dar forma e realizar ideias e projetos artísticos mantendo a máxima do desejo artístico, numa metodologia de otimização. Nestes termos identifico um forte diálogo com as preocupações pontuadas por Miguel Sisto no seu texto sobre as saídas do estereótipo do produtor para uma figura de produtor-gestor no campo artístico.

O texto de Nascimento "Patrimônio
Cultural: uma colaboração para a construção da cidadania de um povo", procura discutir a relevância conceitual e política do patrimônio cultural. A experiência de gestora em espaços institucionais museais no Norte do país e envolvendo um tipo de patrimônio cultural e estético arqueológico e paleontológico, nos situa nas margens da reflexão artística. São relatadas experiências na zona rural e o papel de um patrimônio para aquém da contemporaneidade na constituição de ações culturais atuais. Este texto não está diretamente relacionado ao ofício artístico, mas sua aplicação da desordem temporal - da policronia - revela-se empática aos problemas elencados nas produções, processos e objetos / artefatos artísticos. Como dimensões míticas, paleontológicas e arqueológicas podem ser pensadas para um uso no contexto presente? Desafio da cultura, desafio e prática das artes.

Nestes termos, uma triangulação entre as leituras de Valquiria Guimarães Duarte, Ednair Rodrigues Nascimento e o trabalho do crítico, teórico, historiador, gestor e curador chileno Justo Pastor Mellado parecem de suma importância para as reflexões dadas às artes no que tange aos problemas e desafios da gestão. Mellado, em Escritura funcionaria: ensayos sobre politicas de gestión en arte y cultura (Curatoría Forense, 2013), produz um estudo crítico sobre a sua própria experiência de abertura do Parque Cultural de 
Valparaíso (Chile).

Algumas questões que podemos enunciar a partir da transversalização das problemáticas deste conjunto de textos: O que é instituir e gestionar um equipamento cultural na tessitura complexa de uma cidade (numa cena local)? Como perceber e refletir criticamente sobre os equipamentos de arte e cultura na forma de dispositivos de intervenção no socius? Quais são as estratégias possíveis para uma gestão em face de uma dimensão fabulativa - a da ficção programática (dos conceitos e modelos que estão presentes na concepção de arte e de cultura de seus agentes e nas formas das tradições)? Quais são as formas possíveis de mediação e quais são os agenciamentos que elas promovem? Quando começam e terminam as práticas culturais e estéticas e quando começam e terminam as práticas artísticas, como se articulam?

A gestão é um sistema diagramático e narrativo que visa dar conta das diferentes etapas ou fases de um trabalho artístico. Nela se incluem as questões de administração e de políticas econômicas e políticas públicas para o âmbito da cultura, mas também se integram a elas, os agentes de uma cena local, dos conjuntos procedimentais cotidianos, presentes nas histórias dos projetos artísticos e seus modos efetivos de existir.
Os gestores fazem contínuas negociações entre arcabouço conceitual e mecanismos de administração.

Ao finalizar a leitura deste conjunto dissonante observa-se um patchwork de estudos do campo para os quais a designação da arte e do artístico é ela também uma parte integrante da estratégia política. Incorporar e fazer um ativismo no conceito de arte (artivismo) desde o ponto de vista das demandas de formação para o artista e os agentes do campo das artes, das relações tensas entre as diferentes formas de organização institucional, da organização dos espaços, das experiências e das memórias, um ponto fulcral a que todas estas leituras me convidam.

Todos estes textos estão marcados pela interlocução e exercício multi-, intere transdisciplinar. Consistem por vezes em apanhados e por vezes em leituras sintomais das condições da produção artística em situações periféricas.

\section{III- Ferramentas de trabalho.}

Neste tópico do artigo de reflexão, o que se trata é das ferramentas de trabalho, dos aspectos da metodologia de projetos e das metodologias estratégicas de ação. Em projeto e publicação anterior, tratei de pensar esta temática do 


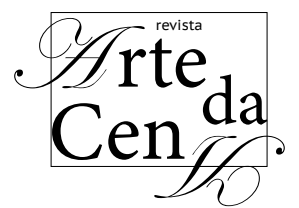

ponto de vista das questões macrossociais e da economia das artes, envolvendo três aspectos da economia (globalização, mercado e sistema e valor, envolvendo aspectos do valor material, do financeiro e do simbólico) e questões da ordem política (política cultural e política pública, ética e política, estética e política, ética e estética, ordem simbólica e ordem tecnológica).

Para este artigo, vou transitar com duas operações entre Mercado (Economia) e Sistema (Política), privilegiando as ferramentas, como se trata de um texto crítico e com número de páginas restrito, aos aspectos desdobrados da artemercadoria, arte-produto e arte-serviço.

Para chegarmos nestes tópicos, vamos pensar algumas das questões que contextualizam a presença de novas formas de organização econômica, envolvendo os aspectos anteriormente estudados - globalização, relações mercados e sistemas, teorias do valor.

No que tange aos aspectos contextuais da globalização, devemos levar em conta que uma economia das artes é quase sempre um fenômeno de globalização, não redutível a seus aspectos materiais ou financeiros, mas perpassando eles, pois sempre envolve uma concepção de arte que exige uma delimitação abstrata e modelada do que sejam as comunidades artísticas. As artes integram grandes sistemas de circulação de capitais, como festivais de teatro e dança e feiras de artes visuais, redes que envolvem modelos para a comercialização, para a distribuição e circulação, bem como grandes sistemas de fomento, que passam quase sempre pela esfera de uma legislação subdividida entre as esferas nacional, regional e local, e os modos atualizados da circulação do capital simbólico, cada vez mais integrado ao capital cognitivo, sob a esfera e a forma da cultura tecnológica (cultura e tecnologia computacional cognitiva).

Estes sistemas complexos configuram o que se chama cenário das novas formas de organização das economias, para as quais o que se denomina de economia cognitiva (envolve história das tecnologias, estudos dos sistemas de crença e de comportamentos, sensologia, análise institucional, socioanálise, análises fenomenológicas do universo econômico) passa a ser estratégico. Há uma redefinição do que seja a cultura mercadológica (o que é um mercado econômico?), envolvendo não apenas os aspectos conhecidos com leis da demanda e.... , mas também teorias cognitivas e teorias da inovação (criação).

Os mercados de arte não podem ser restritos à figura do mercado (no modelo teórico anglo-saxão) e devem ser capazes de incluir redes 
de autoprodução e de autogestão, mecanismos off-market, que devem ser pensados como modos de incorporação de elementos que não conduzem exclusivamente à negociação de fundo monetário (capital financeiro) e da troca mercantil.

Para um entendimento ampliado desta história, deve-se levar em conta duas grandes questões: a primeira, a divisão entre culturas e ethos econômicos protestantes e católicos, os modos como uma delas valoriza fundamentalmente o aspecto do empreendimento (economia do empreendimento, individualismo, liberalismo, economias criativas) e o aspecto das relações entre economia e poder, no controle da economia a partir de um fundo legislativo, na qual toda a economia é fundamentalmente dependente de um conjunto normativo legal (economia estatizada, fomentos públicos e controle sobre os mecanismos do fomento privado por parte do Estado, burocracia). A segunda questão diz respeito às maneiras como o trajeto da globalização esteve sempre acompanhado pela expansão dos sistemas estéticos e de avaliação artística, fazendo das artes um dos potentes mecanismos de tradução entre diferentes culturas e sistemas econômicos, seja como fluxo de bens intercambiáveis materialmente (uma cultura do tráfico de bens artísticos), seja como bens trocáveis comunicativamente (trocas entre práticas e saberes).
Estas questões levam a refletir sobre as diferentes versões ou modelizações dos sistemas das economias simbólicas e seus problemas:

- um deles, a questão das economias do empreendedorismo, o que reduz o papel do Estado na economia dos bens simbólicos ao mesmo tempo que lança a arte para uma relação exclusiva com o mercado e suas flutuações, no limite, gerando uma dependência atual dos sistemas de distribuição e de consumo;

- o segundo, a questão das economias estatais e burocráticas da cultura e das artes, o que amplia o papel do Estado, aumentando os custos de manutenção dos sistemas burocráticos e uma maior lentidão dos processos, não correspondendo em grande parte, às temporalidades distintas dos tempos da criação artística, com aumento da proteção através das políticas de fomentos e subsídios, ao mesmo tempo que, no limite, criam vícios de arregimentação e de estruturas retóricas para a apresentação de projetos;

- e o terceiro, as perversas combinações entre a globalização econômica e a globalização estética, na padronização artística internacionalizada ou na crescente devoração dos sistemas exóticos culturais. Tal como já identificamos em outro texto, na perspectiva de Giorgio Agamben, a ordem global é uma ordem 
universal da estética e da estetização das artes, com o estabelecimento dos critérios universais para o juízo de gosto e os modos como certos objetos são ou não incorporados ao campo artístico, criando a economia do campo erudito.

Estas questões histórico-contextuais são enfrentadas pela expansão de um modo cosmopolita de organização do espaço urbano e sua combinação com um tipo de cidade cognitiva e tecnológica, comum aos traçados explicitados por teóricos marxistas referentes às chamadas economias pós-industriais.

Estas organizações econômicas envolvem uma rede sócio-técnico-cognitiva e colocam relevância no momento do "saber-fazer" que antecede ao momento produtivo. Nesta história tivemos uma fase voltada para uma economia da divulgação (publicitária) fortemente marcada entre os anos 1950 a 1980, e, a partir dos anos 1990, um descenso desta economia de publicização para uma economia de design, escritura e diagramação, valorizando não apenas os aspectos de superfície, mas as causas imateriais, sejam elas tecnológicas, sejam elas interacionais, que se ocultam e antecedem os processos de produção.

Assim, compreende-se a importância crescente dada, separada ou articuladamente, para os aspectos cognitivos (e tecnologias) associadas aos projetos de arte e para os aspectos interacionais, de ordem social, como por exemplo, a relevância dada na avaliação dos projetos artísticos para seus impactos na esfera da tecnologia e para seus impactos de cunho social e inclusivo, ambos ampliando e complexificando as redes de interação.

Podemos e devemos perguntar quais são os caracteres que podemos identificar nos perfis de nossos programas, projetos, produtos e na gestão de bens e de produção artística que permitem a configuração e a manutenção de uma rede de saberes?

Esta é uma questão que pode ser pensada em diálogo com as proposições de Vellozo, quando pontua o desejo de formação associado ao desejo de produção no campo da dança e como a combinação entre estes elementos integra um programa de gestão, no qual a manutenção do trabalho depende da liberação do tempo para a cognição (aprendizagem reflexiva) e para a fruição (gozo da arte), ou, que contamina a reflexão testemunhal do texto de Sisto, no qual a nova figura do produtor exige uma programação prévia, não apenas voltada para um organograma dos produtos (e seus fins), mas de um desdobramento de um sistema de produtos (e um modelo de pensamento ligado ao sistema industrial da cultura) para um sistema de cognição, que pensa 


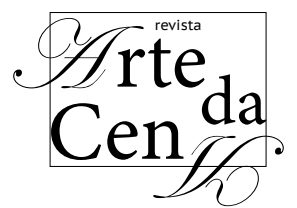

DOI: http://dx.doi.org/10.5216/ac.v2i2.43675

o produto como desdobramento em redes de interação e geração de novas economias, o que também se encontra na perspectiva processual da gestão apresentada no texto de Duarte, contidos neste conjunto.

Tal como aponto em outro texto:

A arte se tornou um lugar privilegiado para as inscrições significantes e para as reinscrições da história - a própria ideia de uma cultura musealizada da arte e de um mundo que, na velocidade, tende a promover e produzir mais e mais culturas de repertório, comparando o museu mais com o depósito do lixo do que com o supermercado. Pois não se trata apenas de consumo de arte e cultura, imposição de uma vertente norte-americanizada de compreensão da realidade, mas que se trata também da manutenção de repertórios e de bancos de informação e de citações. (NORONHA, 2015: 24-25)

O que foi importante até a década de 1990 foi o sistema de consumo, mobilizado por um circuito de distribuição-divulgação / consumo, cujo cerne se encontrava na lógica publicitária (anos 1950 aos anos 1990).

A partir dos anos 1990, com a redução do lugar estratégico de poder da economia da publicidade tal como era realizada, e o crescimento de uma cultura cognitiva de ordem tecnológica, o mais importante passou a ser o sistema de escritura e programação e o mundo mais do que um supermercado passou a ser um lugar para a "catação" de coisas, ideias, bens, objetos, processos de subjetivação, processos de criação, etc.

Numa abordagem macrossocial, o ponto fulcral é o da tensão entre os novos modelos da cultura erudita moderna transformada em cultura curatorial globalizada e suas estratégias de contraconsumo, tendo no curador o papel hegemônico de revalorizar e acentuar a potência do bem cultural que está sendo ofertado, como já disse em outro momento, ressaltando o pacto de singularização, mas ainda dentro - no interior de um sistema erudito da cultura das artes.

Do ponto de vista de uma metodologia de investigação microssocial dos objetos da produção e da gestão artística, podemos ressaltar o exercício de uma fenomenologia do campo econômico e o crescente uso de modelos interacionistas.

O que faz um pesquisador da gestão e da produção artística nestes termos?

Abordar, na construção e na avaliação dos projetos, o potencial da rede de significação que um projeto artístico promove, quando na esfera de juízo público, desde um sentido e significação individual (mas que não ocorre exclusivamente por conta do compromisso do indivíduo consigo mesmo) às tramas de sentido provocadas nas redes de relações, nas redes 
de cognição e na combinação entre ambas (tal como nas redes tecno-sócio-cognitivas), pois nestas esferas podemos identificar e analisar a formação dos mercados de consumo, a formados dos marcadores de gosto (e da volatilidade da opinião), as formas-valor da democratização da cultura, numa forte e constante dinâmica entre interação-interpretação-significação. Procedimentos os mais variados podem ser elencados na pesquisa da gestão e da produção, envolvendo a pesquisa participante, e etnografia, o estudo emotivo-volitivo do gosto, a observação de comportamentos de consumo etc.

Estas investigações etnográficas e etnometodológicas da economia das artes permitem uma leitura complexa do consumo como parte integrante da recepção, não sendo observáveis como puros critérios de consumo, mas formas de entendimento que se traduzem em consumo, em trajetos nos quais os agentes / atores do mundo cultural relatam suas formas de integração, ação e usos sociais da cultura, integrando-as a seus modelos cognitivos, fazendo delas parte do seu repertório cultural pessoal, transformando-as em parte integrante dos seus sistemas de saber e de seus sistemas analíticos da realidade circundante, podendo ainda, em outros graus, gerar indicadores de leitura de contextos e atitudes e práticas reflexivas.
Neste âmbito, estas configurações de análise e de metodologias de pesquisa cognitiva permitem proceder em torno do entendimento das transações que são efetuadas, que não envolvem apenas os produtos, mas também os dispositivos, os hardwares, os modos de reconhecimento que também se fazem presentes e integram a estruturação do campo econômico produtivo. Tanto o método quanto a teoria valorizam e relevam o mercado de informações e, mais do que isso, o mercado da gestão da informação - uma economia fundada em tecnologia de informação.

Este procedimento metodológico não é de caráter tipológico. Ele não pretende estabelecer um macro-modelo analítico para as flutuações e comportamentos econômicos, dentro dos domínios da gestão e da produção. Sua perspectiva é a do tratamento por meio de representações parciais e suas recombinações. Por exemplo, como abordar a perspectiva tradicionalista dos estudos de demanda (O que o mercado oferece? O que o consumidor procura? Etc.) combinados à perspectiva de uma exigência de especialização profissional e de mercados (exigência de formação, por exemplo, como aponta o texto de VELLOZO, neste conjunto de artigos) e aos processos de valoração de um artista e das suas obras, determinando um valor simbólico e um valor econômico (material e ou financeiro) das obras artísticas? Como estas 
questões se combinam e recombinam a cada momento? O que devemos considerar num contexto de análise? Uma maior especialização e formação de um artista e de um conjunto de artistas afeta o mercado de bens artísticos e o próprio mercado de trabalho? E de que modo? A cultura e os avanços da economia cognitiva podem modificar a cultura dos investimentos em artes? A presença de festivais de teatro e de dança podem ser fatores para o aquecimento do setor de investimentos numa cosmópolis?

E haveria uma alternativa ou uma forma completar ao sistema da economia cognitiva na forma de um sistema de economia de interações? Em projetos cujo eixo não é fundamentalmente a tecnologia de informação mas a ampliação da socialização, temos outros elementos para análise. Um bom exemplo destas questões se encontra nas obras de Richard Sennet. Na leitura de Juntos, observa-se uma história sociológica do econômico, valorando a flexibilização de aspectos que transitam entre o modelo estatizado (afrancesado) e o modelo liberal (anglo-saxão), na criação de mecanismos denomináveis de antimercadológicos, que aquecem a economia por meio de mecanismos legais, tais como as leis de fomento e os programas e fundos, mas também as formas colaborativas de fomento e financiamento.

Esta é a combinação que venho identificando como sendo entre artista produtor e consumidor democrático e artista transgressor (artista terrorista) e consumidor transgressor. O primeiro deles é representado pela figura emblemática do turismo e do turista (numa economia de afluência do mercado internacional de cultura e da cultura como forma de turismo) e o segundo representado pelo sistema das artes e suas formas de contraconsumo.

Muitos casos podem ser relatados. Não vou me deter num deles, mas vou identificar algumas análises que são fecundas para este tipo de abordagem.

Por exemplo, os estudos de Thierry Gaudin sobre o papel da cosmópolis e a presença e localização dos aeroportos e seu impacto tecnológico e cultural, como despesa entendida sob a égide de valor agregado no âmbito da produção cultural.

De outro lado, o trabalho de Justo Pastor Mellado sobre a gestão em arte e cultura e a sustentabilidade das cenas locais.

Em todos eles, sempre está em jogo um capital cognitivo, seja como interação, seja como tecnologia e impacto tecnológico, seja como rede intersubjetiva e ação social dos saberes, seja como memória coletiva e trabalho dos afetos 
nas comunidades (o caso do parque cultural de Valparaíso descrito por Mellado ressalta em vários momentos estes aspectos).

A preocupação central é a de uma economia cognitiva que, como diz Mellado, possa incidir sobre a cena artística local. Na opinião deste importante teórico latino-americano, um artista que sustenta um capital formal em relação ao seu próprio trabalho integra uma rede mais consistente de gestão dos espaços da arte na cidade, ultrapassando a perspectiva comumente adotada de transformar espaços públicos em zonas marginais de sobrevivência para artistas extra-mercadológicos incapacitados de inscrição histórica nas economias produtivas. O que está em jogo, não é transformar os espaços públicos, em locais de mendicância, ou, lugares para a exibição de programas que não podem ser integrados em outros circuitos da economia. Os lugares públicos não podem ser reféns da precariedade dos espaços de exposição, demonstração, apresentação artísticas. (MELLADO, 2013)

Qualquer ação cultural e artística integra o imaginário de comunidades e integra a produção de seus relatos e de seus aparatos de cognição, tornando-se parte integrante dos repertórios socialmente compartilhados.

Estas e outras questões exigem a instalação dos observatórios, alguns deles já existentes no caso brasileiro, em grandes centros urbanos (o caso do Observatório Itaú em São Paulo). Os observatórios parecem ser o lócus adequado às exigências dos sistemas e economias artísticas. As experiências e reflexões em torno da gestão estratégica, narrativas, identidades, etc., pontuadas nos textos de Duarte e de Nascimento, são bons exemplos de um debate de como objetos culturais e transculturais (no caso de Nascimento) podem conter um ativador narrativo imaginário capaz de promover deslocamentos sintomais de uma comunidade. Teatros, espaços expositivos, parques culturais, centros de arte e de cultura, museus, etc., equipamentos de cultura e de arte, precisam refletir sobre potencialização e capacidade de transformação dos espaços existentes em espaços de atração, não somente de entretenimento, mas também de memória.

\section{IV- Projeto editorial - encerramento e}

\section{novas aberturas.}

A última parte deste texto se dedica especificamente a apontar a organização deste conjunto de textos em particular. Resultantes de um projeto cultural e artístico do Fundo Cultural do Estado de Goiás, teve como integrantes Ilze Petroni, Erandi Fajardo, Jorge Sepúlveda, Guillermina Bustos, Miguel Sisto Junior, Ednair Nascimento e Marcio Pizarro Noronha (como 


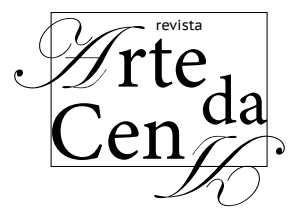

integrante da equipe, proponente e gestor). Integraram-se na versão final deste trabalho as pesquisadoras acadêmicas Valquiria Guimarães Duarte (UFG) e Marila Vellozo (UNESPAR). Todos estes trabalhos se encontram situados num contexto latino-americano de reflexões sobre as políticas públicas e as economias da cultura, bem como as políticas para as artes e os sistemas e economias das artes. As esferas do econômico e do político, de modos os mais diversos, estão integrados às preocupações da fabricação das obras artísticas, das formas da crítica e nas práticas curatoriais dos tempos recentes.

Sabemos que o debate sobre as artes enfraqueceu na esfera pública tal como entendida por Habermas. O jornalismo cultural encontra-se pobremente atrelado ao entretenimento. Assim, pensar em gestão, produção, crítica, curadoria, dependem de outros espaços, tais como as revistas universitárias, os blogs e sites, lugares especializados.

Há um gesto de urgência em discutir gestão e produção ao mesmo tempo que a velocidade da própria produção cultural impede a qualificação teórica e metodológica e exige o puro estado do trabalho cumulativo de produzir.

Este conjunto de artigos, de forma pequena, pretendeu reunir alguns arquivos reflexivos a partir de relatos e de documentação, garantindo uma nova vida ao projeto de Gestão em Arte e Cultura.

O diálogo, a documentação e o produto material que resultam desta parceria com a revista Arte da Cena integram um programa gestor ele próprio, na perspectiva de dar nova vida ao projeto e aos desdobramentos do fomento. Neste domínio, apresentamos um conjunto de textos na sua versão de publicação eletrônica (revista científica eletrônica). Para o porvir, serão gerados ainda uma publicação impressa deste número da Revista, na forma de livro, para distribuição gratuita, e um e-book, com uma versão ampliada, no formato livro, exclusivamente de textos voltados para a economia, a gestão e a produção das artes e da cultura.

Para finalizar este artigo que é também um texto de apresentação, quero agradecer aos Editores e colegas da Revista Arte da Cena, nossos parceiros nessa empreitada, pelo apoio e compreensão na longa tarefa de organização do material a ser publicado. 


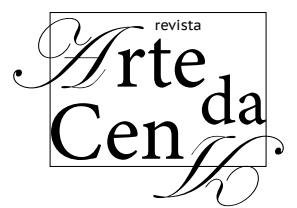

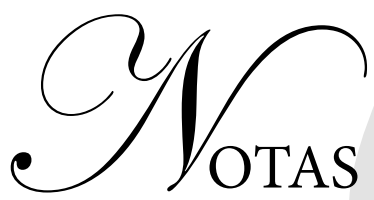

1 Curatoría Forense es un grupo multidisciplinario de trabajo dedicado al arte contemporáneo en Latinoamérica desde 2005, orientada ala construcción de una red a partir de la creación y consolidación de relaciones afectivas y efectivas y la promoción de la producción y circulación de conocimiento e interacciones con el objetivo de triangular arte contemporáneo y debate con la comunidad. SÍTIO: http://www.curatoriaforense.net/niued/

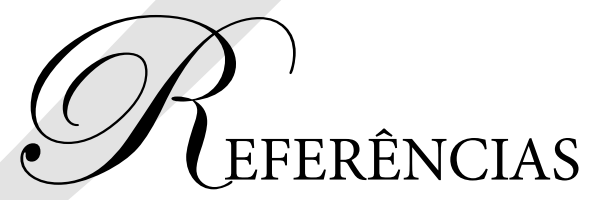

DUARTE, Valquíria G. Uma História Edificada: Tríplice Mimese e Performance. Um Estudo Narrativo da Fundação Iberê Camargo (Porto Alegre-RS, 1998-2008), de Álvaro Siza. Tese (Doutorado) - Programa de Pós-Graduação em História da Universidade Federal de Goiás. Goiânia, 2013.

GREFFE, Xavier.(2013)Arte emercado. SãoPaulo: Iluminuras. (coleção Observatório Cultural Itaú)

LADDAGA, Reinaldo. (2012) Estética da emergência: a formação de outra cultura das artes. São Paulo: Martins Fontes (selo Martins).

MELLADO, Justo Pastor. (2013) Escritura funcionaria: ensayos sobre politicas de gestión em arte y cultura. $1^{\mathrm{a}}$. Edición. Córdoba: Curatoría Forense.

NORONHA, Marcio Pizarro. (2015) Economia das artes. Goiânia: Gráfica Qualicor. 2a . Edição. Publicação da Lei Municipal de Incentivo à Cultura de Goiânia.
VELLOZO, Marila e GUARATO, Rafael. (org.) (2015) Dança e política: estudos e práticas. Curitiba: Kairós. Publicação de Projeto do Fundo Estadual de Cultura de Goiás.

* MARCIO PIZARRO NORONHA é professor e pesquisador da Universidade Federal de Goiás, da Faculdade de Educação Física e Dança e do Programa de Pós-Graduação em História da Faculdade de História da UFG. Coordena o grupo de pesquisa CNPQ UFG INTERARTES PROCESSOS E SISTEMAS INTERARTÍSTICOS EESTUDOSDEPERFORMANCE. Fez formação em história, antropologia e psicanálise e atua em atividades curatoriais e de crítica das artes. Email para contato: pizarronoronha@gmail.com 